\title{
Ensino e aprendizagem de Biologia: estudo de caso da exposição "O Brasil na Antártica" realizada na Universidade Veiga de Almeida
}

\author{
Ana Carolina Volpato Zanandrea \\ Bruna Mayato Rodrigues \\ Graduada do curso de Ciências Biológicas - Licenciatura. \\ Universidade Veiga de Almeida - Tijuca. Rio de Janeiro, RJ \\ Brasil. \\ E-mails: aquizanandrea@gmail.com \\ brunamayato@gmail.com \\ Universidade Veiga de Almeida; Universidade Veiga de Almeida - \\ Tijuca. Rua Ibituruna, 108. Rio de Janeiro, RJ, Brasil \\ Alexandre Santos de Alencar \\ E-mail: alexandre.alencar@uva.br
}

Recebido em: 16 abril 2018. Aceito em: 16 maio 2018.

DOI: http://dx.doi.org/10.21674/2448-0479.43.487-500

\section{Resumo}

A tendência proposta para a educação brasileira apoia o uso de diferentes instrumentos didáticos para o ensino, sendo que, exposições mediadas, além de serem uma forma de divulgação científica, podem servir para alunos assimilarem conhecimentos de forma multidisciplinar. Para testar esta hipótese e visando ampliar a divulgação de atividades científicas realizadas no Continente Antártico, foi instalada na UVA, a exposição mediada "O Brasil na Antártica". A exposição recebeu 202 alunos do Ensino Médio, que responderam a um questionário sobre a Antártica, sendo dividido em grupos de respostas antes e após a mediação. Também foi mantido um perfil no Facebook ${ }^{\circledR}$ para divulgar a exposição. A comparação das respostas demonstrou aumento na porcentagem de acertos após a mediação para a maioria das questões. $\mathrm{O}$ uso da exposição mediada como instrumento didático se mostrou uma forma válida de complementar os conteúdos vistos em sala de aula.

Palavras-chave: Multidisciplinaridade. Mediação. Redes sociais. Antártica. 


\section{Abstract \\ Teaching-learning process of Biology: a case study of the exhibition "Brazil in Antarctica" held at Veiga de Almeida University}

The proposed trend for Brazilian education supports the use of different didactic instruments for teaching. Mediated expositions besides being a form of scientific dissemination can also serve for students assimilate knowledge in a multidisciplinary way. To test this hypothesis and in order to expand the dissemination of scientific activities carried out in the Antarctic Continent, the mediated exhibition "Brazil in Antarctica" was installed in the UVA. The exhibition received 202 students from High School, who answered a questionnaire about Antarctica, being divided into groups of responses before and after mediation. A Facebook ${ }^{\circledR}$ profile has also been maintained to publicize the exhibit. The comparison of responses showed an increase in the percentage of correct answers after mediation for most of the questions. The use of mediated exposure as a didactic instrument proved to be a valid way of complementing the contents seen in the classroom.

Keywords: Multidisciplinary. Mediation. Networks. Antarctica.

\section{Introdução}

O Ensino Médio é a etapa final da educação básica e, conforme definida pela Lei de Diretrizes e Bases da Educação Nacional, possui diversas finalidades, tais como: a consolidação e o aprofundamento dos conhecimentos adquiridos no ensino fundamental; o desenvolvimento da autonomia intelectual e do pensamento crítico; e a compreensão dos fundamentos científicotecnológicos dos processos produtivos, relacionando a teoria com a prática, no ensino de cada disciplina (BRASIL, 1996). A definição legal é abrangente e elogiável, mas, transformar o escrito em ação é uma árdua tarefa, que demanda tempo e empenho.

Para auxiliar na concretização efetiva das diretrizes previstas na legislação que regulamenta o ensino médio foram disponibilizados os Parâmetros Curriculares Nacionais (PCN), que objetivam difundir os princípios da reforma curricular e orientar o professor na busca de novas abordagens e metodologias (BRASIL, 2000). Resumidamente, o PCN se propõe, neste contexto, a desenvolver as capacidades relativas às pesquisas, isto é, saber buscar as informações e analisá-las e estimular a aprendizagem, criação e formulação de ideias, ao invés de simplesmente estimular o exercício da memorização.

Recentemente redigida, a Base Nacional Comum Curricular (BNCC) também visa à formação de cidadãos para o século XXI. A BNCC é um conjunto de orientações que norteia os currículos das escolas, redes públicas e privadas de ensino de todo o Brasil, descrevendo os conteúdos que os alunos devem aprender e habilidades a desenvolver a cada etapa da Educação Básica, da Educação Infantil ao Ensino Médio (MEC, 2018). 
Em relação à disciplina de Biologia, conforme definido por lei e proposto pelo $\mathrm{PCN}$, ao concluir o ensino médio, os alunos devem conhecer seus conceitos básicos e estar capacitados a articular o seu pensamento de forma independente, aplicando os conhecimentos adquiridos nos estudos biológicos ao seu cotidiano e intervindo para resolver os problemas propostos sobre o tema.

Do ponto de vista educativo, a Biologia deve ser encarada como fundamental na formação geral do cidadão, por se ocupar do estudo da vida ou talvez com mais propriedade, do estudo dos sistemas vivos. Veríssimo, Pedrosa e Ribeiro (2001) explicam que a liberdade de formular opções (éticas, socioeconômicas e políticas) depende do grau de literacia, também biológica, do cidadão. Esta interdependência liberdade-literacia biológica é particularmente determinante nas questões atinentes ao futuro da espécie humana e ao meio ambiente.

A tendência proposta para a educação brasileira com relação ao processo de ensino e aprendizagem parece seguir na linha das abordagens construtivistas ou cognitivistas e socioculturais, buscando atender às variações regionais e respeitando o projeto político pedagógico elaborado por cada escola, mesmo que esta não use destas metodologias de ensino. Ambas as teorias possuem liberdade nas técnicas usadas, havendo um consenso de que a educação em Ciências tem muito a ganhar com a participação de instâncias educativas de caráter não formal (QUEIROZ et al., 2002).

Para tal, não há rigidez nos procedimentos de ensino, permitindo que o professor use de diferentes estratégias, variedades de materiais didáticos e instrumentos de ensino para propiciar melhor eficiência do processo ensino-aprendizagem. Como apontado por Krasilchik (2008, p. 77), sobre a prática de ensino de Biologia,

Qualquer curso deve incluir uma diversidade de modalidades didáticas, pois cada situação exige uma solução própria, além do que a variação das atividades pode atrair e interessar os alunos, atendendo às diferenças individuais.

A mesma autora destaca ainda que a escolha da modalidade didática depende do conteúdo e dos objetivos selecionados, da classe a que se destina, do tempo e dos recursos disponíveis, além dos valores e convicções do professor.

De acordo com Souza (2014), cabe ao professor adaptar suas práticas à utilização destas ou daquelas modalidades didáticas, uma vez que as possibilidades para melhorar a qualidade do ensino são muito variadas. A autora analisou as principais modalidades didáticas encontradas na literatura e, entre os instrumentos didáticos, cita que as excursões ou trabalhos de campo são ótimas alternativas para socialização entre os alunos e também para quebrar a rotina da sala de aula. Excursões podem ser realizadas para visitar exposições, como de museus ou montadas em espaços temporários, sendo particularmente interessantes quando possuem mediação. Nestes espaços, mediar é estimular diálogos entre o observador e os materiais expostos, provocando reflexões internas sobre seus próprios conhecimentos e promovendo novas aprendizagens aos visitantes. O mediador pode colaborar preenchendo o vazio que muitas vezes existe entre o que foi idealizado e a interpretação dada pelo público ao que está exposto (QUEIROZ et al., 2002). 
Com o objetivo de ampliar o conhecimento sobre as atividades científicas realizadas no Continente Antártico por pesquisadores brasileiros, foi instalada no Rio de Janeiro a exposição multidisciplinar "O Brasil na Antártica". O principal foco da mostra foi o de apresentar um pouco da rotina de pesquisa e das condições que são enfrentadas na Antártica não só para a comunidade da Universidade Veiga de Almeida (UVA), mas também para visitantes. Além disso, como forma de divulgação e, para compartilhar as atividades desenvolvidas durante a exposição, foi criado um perfil na rede social Facebook ${ }^{\circledR}$ (https://www.facebook.com/brasilantartica/).

A Antártica é um continente dedicado à paz e à ciência, além de desempenhar um papel de destaque nas questões de mudanças climáticas verificadas em escala global. Com a evidência cada vez maior da degradação que estava ocorrendo na Antártica, foram criados tratados entre países visando a proteção do continente gelado.

Em 1959, foi assinado o Tratado da Antártica, mas, em 1991, este foi revisado e o foco de interesse foi modificado. A discussão sobre como dividir a Antártica deu lugar às discussões sobre as melhores maneiras de preservá-la. Assim, foi criado um Protocolo ao Tratado da Antártica sobre proteção ao meio ambiente, conhecido como Protocolo de Madri. Este novo tratado entrou em vigor em 1998, substituindo e ampliando as medidas acordadas para a conservação da fauna e flora antárticas, proporcionando maior proteção ambiental a toda a região Antártica (MACHADO e BRITO, 2006).

O Brasil aderiu ao Tratado da Antártica, em 1975, porém o Programa Antártico Brasileiro (PROANTAR) só começou a realizar pesquisas na região em 1983. Ao ratificar o tratado, o Brasil assumiu compromissos internacionais que o obriga a realizar pesquisa científica e a preservar o meio ambiente antártico (BRITO, 2006). Os estudos desenvolvidos ao longo dos últimos anos no continente visam compreender as características únicas da região e identificar o efeito das mudanças globais sobre os diversos ecossistemas.

No contexto do PROANTAR, pesquisadores brasileiros desenvolvem diversas atividades científicas em diferentes áreas do conhecimento, como biologia marinha, ecologia de aves, oceanografia biológica, botânica, química da atmosfera, efeitos das atividades antrópicas, entre outras. Para auxiliar professores dos mais diversos níveis da Educação a levarem mais informações sobre o Continente Antártico para dentro da sala de aula, a Associação de Pesquisadores e Educadores em Início de Carreira sobre o Mar e os Polos (APECS-Brasil) formulou um tutorial que inclui atividades que estão em consonância com o currículo escolar brasileiro, numa tentativa de contribuir com as dinâmicas de ensino vigentes, além de superar a defasagem de conteúdos relacionados aos ambientes polares observada nos livros didáticos da educação básica (CARAMELLO et al., 2017). Assim, a Antártica se apresenta como um tema que proporciona o estudo de Biologia de forma ampla, capaz de englobar vários assuntos.

A legislação brasileira também contempla a importância do Meio Ambiente no capítulo VI da Constituição, no artigo 225, segundo o qual todos têm direito ao meio ambiente ecologicamente equilibrado, bem de uso comum do povo e essencial à sadia qualidade de vida, impondo-se ao Poder Público e à coletividade o dever de defendê-lo e preservá-lo para as presentes e futuras gerações (BRASIL, 1988). 
Outro fator motivador é que, em 2002, foi regulamentada a Lei da Política Nacional de Educação Ambiental, através do Decreto 4.281 do poder executivo. Esta lei, em seu Artigo V, trata da inclusão da educação ambiental em todos os níveis de ensino, especificando seus princípios gerais e as competências dos órgãos públicos e privados e, o Artigo VI, trata dos programas de educação ambiental integrados às diversas atividades que envolvem a questão ambiental (OLIVEIRA, 2006).

Considerando a importância da constante reflexão do processo de ensino e aprendizagem, aliado ao preconizado na legislação e nos documentos normativos da educação brasileira, o presente trabalho buscou compilar informações para ampliar a discussão sobre o ensino de Biologia, tendo como base o estudo de caso da referida exposição.

\section{Material e Métodos}

Desenvolvida no contexto do projeto de extensão "UVA GELADA", a exposição mediada intitulada "O Brasil na Antártica" esteve aberta para visitação do público na Universidade Veiga de Almeida - Campus Tijuca, entre os dias 26 de fevereiro e 25 de março de 2016. Durante este período a exposição foi visitada por cerca de 500 pessoas, representadas principalmente por alunos do ensino médio, por estudantes e por funcionários da UVA. A exposição foi composta por fotografias com paisagens e animais antárticos, pôsteres sobre as pesquisas realizadas, vestimentas polares (utilizadas em ambientes antárticos), material planejado para atender o público infanto-juvenil e uma maquete do Criosfera 1. Este último representa um módulo de pesquisa instalado no interior do Continente Antártico, que realiza monitoramento atmosférico ininterrupto, sendo este um fator-chave para a melhor compreensão das variações climáticas verificadas na Antártica.

Um diferencial desta exposição foi a participação de 13 acadêmicos do curso de Ciências Biológicas da UVA, atuando voluntariamente como mediadores. A equipe oficial de mediadores foi formada após a realização de um workshop de capacitação dos acadêmicos para a exposição. 0 workshop incluiu aulas teóricas e uma saída externa para visita ao Museu Nacional, na qual os mediadores voluntários puderam conversar e receber orientações dos profissionais do museu, que possuem larga experiência em mediação de diferentes públicos alvos.

O processo de mediação ocorreu em duplas ou trios de mediadores que previamente dividiam os pontos sobre qual cada um iria abordar, por exemplo, um focaria nas fotos e o outro na maquete e vestimentas. Primeiramente, as turmas eram recepcionadas com a apresentação dos mediadores, que estimulavam os alunos a comentarem sobre o que conheciam sobre o Continente Antártico. Após esta etapa, iniciava-se a mediação por algum ponto que a turma demonstrou interesse. Durante toda a visita, os alunos eram incentivados a interagir com os mediadores para demostrarem seus conhecimentos sobre o tema da exposição.

Através de uma parceria entre o curso de graduação em Ciências Biológicas e o projeto Vivenciando da UVA, um questionário foi aplicado para turmas que, durante o período da exposição, estiveram na universidade. O projeto Vivenciando é voltado especialmente para os alunos de Ensino Médio que visitam a universidade com o objetivo de conhecer, observar e interagir com o ambiente 
universitário. De acordo com o tempo disponível para que cada grupo de alunos pudesse acompanhar a exposição mediada, foram estabelecidos dois momentos distintos para aplicar o questionário: imediatamente antes do início da mediação ou depois da visita mediada dentro do período que os alunos permaneceram na UVA. Os estudantes foram convidados a responder o questionário, sendo informados para que fim seriam usadas as respostas e que poderiam escolher livremente em participar ou não.

O questionário continha 10 perguntas fechadas de múltipla escolha com apenas uma opção de resposta correta. O mesmo foi adaptado de um questionário elaborado pela APECS-Brasil, composto por questões sobre os polos, o clima na Antártica, flora e fauna austral. Também foram feitas perguntas de perfil, apenas com intuito de identificar o sexo, idade e série que frequenta, preservando o anonimato do aluno. A mediação não seguia um roteiro especificamente relacionado com as perguntas do questionário, sendo que os mediadores apresentavam os pontos chaves, mas estes podiam ser flexibilizados de acordo com a interação com a turma e o tempo disponível para visitar a exposição.

No total foram respondidos 202 questionários e os dados obtidos foram analisados estatisticamente de forma quali-quantitativa, utilizando o software Excel. O número de respostas corretas foi transformado em porcentagem e a normalidade da distribuição dos dados foi verificada e aceita pelo teste de D'Agostino \& Pearson $(\alpha=0,05)$. Foi usado o Teste-t para duas amostras em par para médias com $95 \%$ de confiança $(\alpha=0,05)$ para verificar se ocorreu diferença de acertos entre 0 grupo de respostas antes e após a mediação. Este Teste-t permite inferir sobre a igualdade de médias de duas amostras emparelhadas formando pares de observações, verificando se existem diferenças entre o comportamento de grupos testados em dois momentos distintos: antes e depois de um tratamento ou intervenção.

Para minimizar possíveis distorções, neste estudo buscou-se o máximo de homogeneidade entre os grupos analisados, uma vez que todos eram alunos do terceiro ano do Ensino Médio de escolas privadas do município do Rio de Janeiro. A comparação de médias ao final de testes sempre é passível a críticas de que a diferença ou igualdade verificada é espúria e decorrente de outros fatores que atuam sobre as amostras (BEIGUELMAN, 2002).

Como forma de analisar a abrangência da divulgação por rede social foram utilizadas informações que são oferecidas pelo Facebook ${ }^{\circledR}$ ao administrador da página dentro do ambiente de gerenciamento. Porém, nem todos os dados disponíveis foram obtidos, uma vez que existe uma

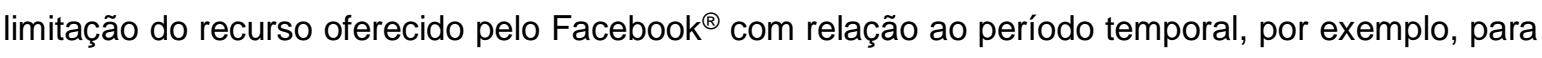
alguns dados apenas as quatro últimas semanas observadas ficam armazenadas e a visão geral das informações é um resumo de sete dias sobre as atividades mais importantes na página. 


\section{Resultados e Discussão}

Foi verificada significativa participação dos alunos do Ensino Médio visitantes da exposição mediada, pois, apesar de provavelmente terem estudado algum tópico sobre o Continente Antártico, dúvidas, equívocos e curiosidades sempre surgiram. A figura 1 ilustra alguns momentos de interação entre os mediadores e as turmas.

Assim como os alunos visitantes tiveram oportunidade de expandir seus conhecimentos, os alunos da UVA que participaram como mediadores passaram por uma experiência incomum na rotina acadêmica. A construção da exposição e a mediação representaram importantes momentos para a sua formação acadêmica, uma vez que os mediadores desenvolveram diferentes atividades para construir e aprimorar suas práticas didáticas, bem como suas relações com os estudantes e com o processo de ensino-aprendizagem.

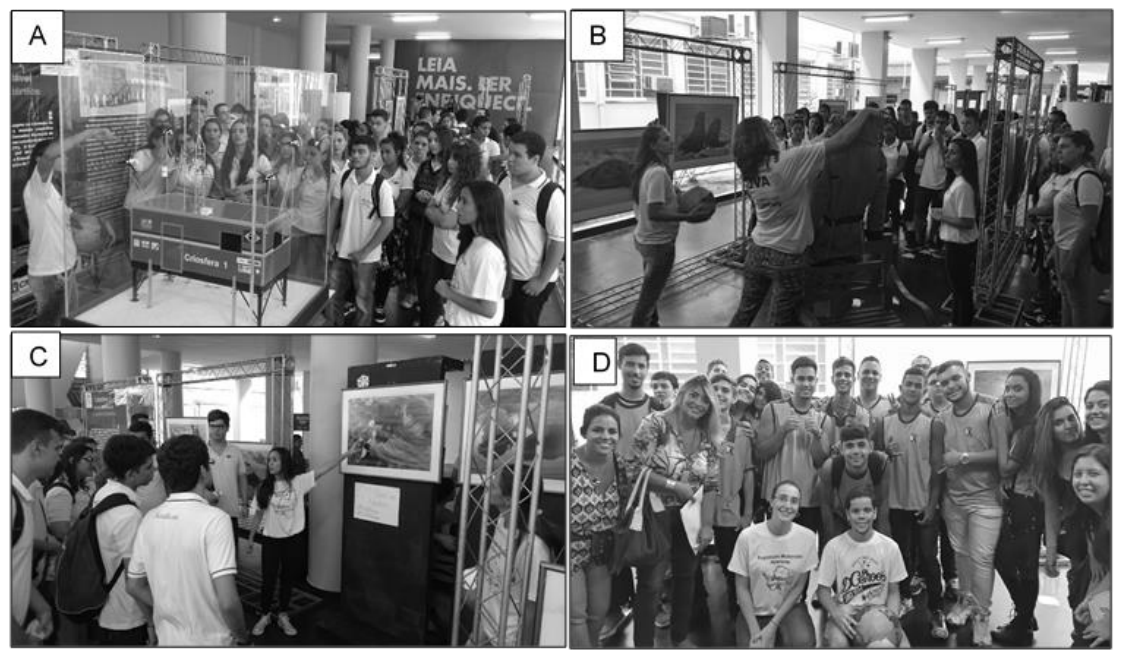

Figura 1 - Fotos das turmas de Ensino Médio participando da mediação. A) mediadora explicando a maquete do Criosfera 1; B) mediadora demonstrando os detalhes de uma roupa polar; C) mediadora transmitindo informações sobre a foto com uma pesquisadora na Antártica e D) mediadores e turma após a visita guiada. Fonte: $\mathrm{O}$ autor, 2016.

\section{- Análise dos questionários}

A análise dos questionários respondidos pelos estudantes do Ensino Médio que participaram da exposição mediada demonstrou que, para a maioria das questões, o porcentual de acertos foi maior após a mediação, apenas com exceção das questões sete e nove (Figura 2). 


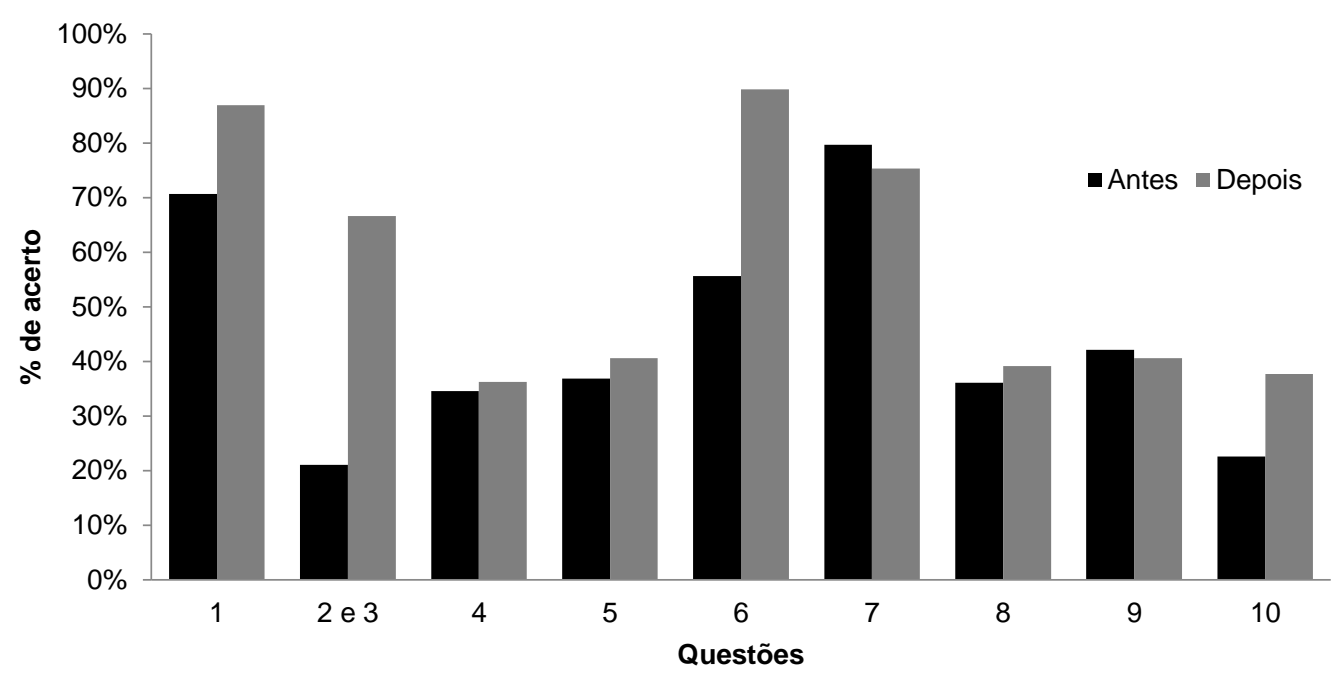

Figura 2 - Gráfico da porcentagem de acertos ao questionário antes e após a mediação.

A análise das repostas relacionadas à questão seis (6. O Brasil tem uma estação de pesquisa polar. Onde ela fica?) mostrou um aumento de acerto significativo. A verificação do aumento da porcentagem de acertos de $56 \%$ para $90 \%$ é uma evidência de que os alunos assimilaram a explicação durante a mediação. Este aumento foi estatisticamente significativo $(P=0,01)$, observado através do Teste-t para dados pareados.

Com relação às questões que não obtiveram maior porcentagem de acertos após a mediação, a questão sete indagava: Por que os ursos polares não comem pinguins? Antes da mediação $80 \%$ dos participantes acertaram a resposta e após $75 \%$. Esta não é uma diferença estatisticamente significante de acertos antes e após a mediação $(P=0,14)$, verificada pelo Teste-t para dados pareados. Como a questão trata de uma curiosidade que é frequentemente divulgada por diversas mídias, acreditamos que a maioria dos alunos já sabia que os ursos polares vivem no Ártico (Hemisfério Norte) e os pinguins na Antártica (Hemisfério Sul). Porém, não foi verificado aumento na porcentagem de acertos após a mediação, o que indica que para uma parcela dos alunos esta informação não foi mencionada ou não a apreenderam.

Sydney (2008), ao realizar uma oficina interativa com alunos dos Ensinos Fundamental e Médio com o objetivo de esclarecer dúvidas e desmistificar algumas concepções de senso comum sobre os mamíferos marinhos, além de mostrar como as pesquisas são realizadas numa tentativa de aproximação da sociedade com o meio científico, aplicou um questionário antes e ao término da oficina. A pesquisadora conseguiu observar que no questionário inicial nenhum aluno obteve $100 \%$ de acerto, ao passo que no questionário final, $14 \%$ deles acertaram todas as questões, tendo a maioria cometido apenas um erro $(38,6 \%)$ e nenhum errou mais do que quatro questões. No presente estudo, não 
obtivemos nenhum questionário com acerto total, assim como nenhuma das questões atingiu $100 \%$ de acerto entre os informantes.

Os problemas ambientais são grandes preocupações da atualidade. Por isso, uma questão destacada para análise isolada é a de número cinco, que pergunta sobre que regiões apresentam significativa influência sobre o clima no planeta Terra. Essa pergunta é importante por estar relacionada com um tema que está constantemente nos meios de comunicação: as Mudanças Climáticas Globais. Verificou-se que em torno da metade dos alunos considerou que o Ártico e a Antártica influenciam no clima do planeta Terra, mesmo após a mediação (Figura 3). No entanto, apenas a Antártica produz esta influência planetária, o Ártico influencia apenas áreas próximas a sua localização. Oliveira (2006) apresenta uma abordagem pertinente com o contexto das mudanças climáticas e a Antártica, na qual diz que devemos considerar o planeta Terra como uma totalidade em movimento, onde a modificação, a deterioração ou a exaustão dos recursos naturais ou a transformação dos ecossistemas, não atingem somente um grupo social em cujo espaço geográfico se produz, mas sua repercussão se dá na totalidade do sistema. Ou seja, os problemas ambientais não afetam a um ou outro país isoladamente, mas transcendem os limites geopolíticos.

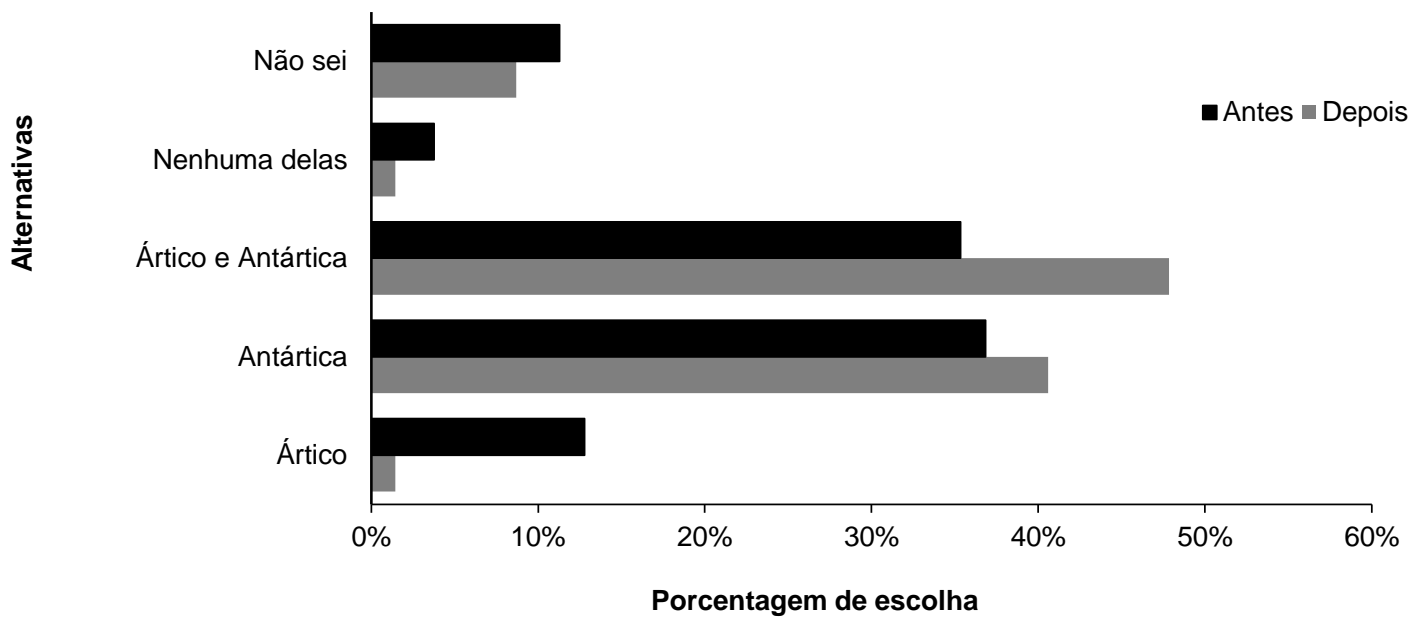

Figura 3 - Gráfico da porcentagem de escolhas por alternativa da questão número cinco.

Desta forma, a Antártica recebe perturbações de ações oriundas das áreas mais povoadas do planeta. Isto torna o Continente Antártico um local especial e único para estudo, pois, além de ser considerado um eficiente local para registro da história climática do planeta, pode nos fornecer dados suficientes e em resolução adequada para prever as mudanças climato-ambientais futuras (RODRIGUES et al., 2014). Conhecer melhor e monitorar o meio ambiente antártico são ações fundamentais para a construção de cenários futuros (MMA, 2007). Machado e Brito (2006) acreditam que os efeitos da ação humana se tornam, a cada dia, mais evidentes e de reversão mais improvável, 
sendo que apenas a tomada de consciência - que só se dá pela Educação - seja a chave para mudanças reais de paradigmas.

\section{- Análise dos dados de navegação da rede social Facebook ${ }^{\circledR}$}

Em relação à divulgação da exposição através da página "O Brasil na Antártica" na rede social Facebook $^{\circledast}$, observou-se que 177 pessoas clicaram na opção de curtir a página entre 23 de fevereiro e 01 de novembro de 2016, revelando o interesse em acompanharem as publicações sobre a exposição. Este número aponta para um alcance máximo de 567 pessoas, conforme cálculo realizado pelo próprio sistema, indicando que a interação das pessoas que curtiram a página pode influenciar outras pessoas a acompanharem as publicações. Conforme explicado na própria página do Facebook $^{\circledR}$ para 0 administrador, as publicações que recebem mais curtidas, comentários e compartilhamentos aparecem com mais frequência no feed (mural) de notícias e são vistas por mais pessoas. Desta maneira, o alcance total é referente ao número de pessoas que receberam alguma atividade da página, incluindo publicações dos administradores, publicações de outras pessoas na página, anúncios para curtir página, menções e check-ins.

Com relação aos dados relativos ao alcance total das publicações (Figura 4), conforme explicado por Monteiro (2016), refere-se aos seguidores que curtiram a página por terem visto publicações de amigos no "feed de notícias" ou por terem seguido o endereço que foi divulgado do evento, o que é referido pelo Facebook ${ }^{\circledR}$ como "orgânico", quando não é realizada qualquer propaganda paga da página para atrair seguidores, que seria destacada no gráfico como "pago".

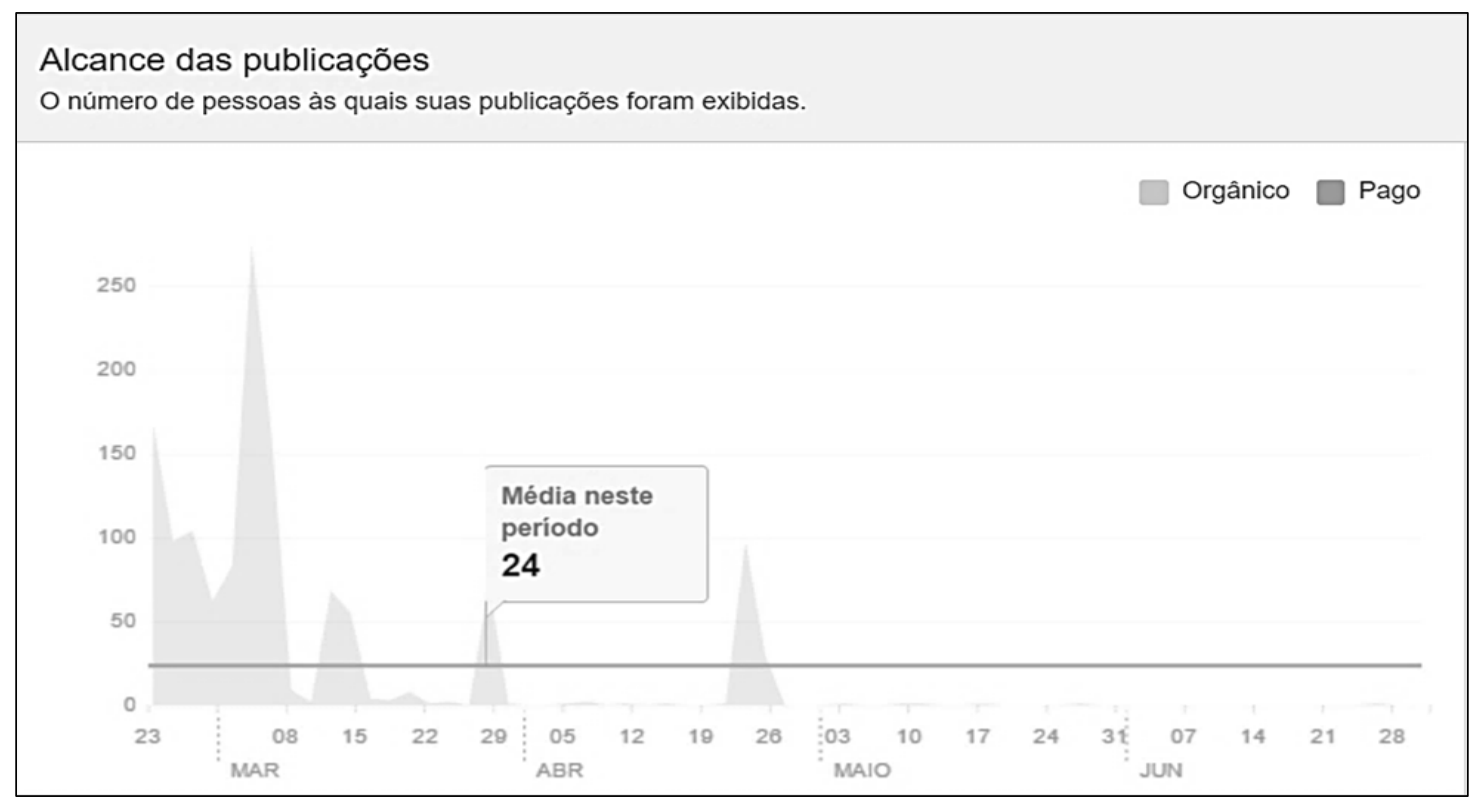

Figura 4 - Gráfico do alcance total das publicações no perfil da exposição na rede social Facebook ${ }^{\circledR}$ entre 23/02/2016 a 01/07/2016. Fonte: https://www.facebook.com/brasilantartica/insights/ 
Nota-se que o período de maior alcance foi durante os dias da exposição. Apesar de haver um pico de alcance das publicações postadas no perfil antes da abertura da exposição, no dia 23 de fevereiro de 2016, o pico máximo ocorreu após o início das visitas mediadas, entre 04 e 08 de março de 2016. Esta observação demonstra que a possível divulgação do evento não ocorreu antes da sua abertura, mas sim, após o público ter acesso a exposição. Este fato pode ter ocorrido devido ao aumento de postagens com fotos de pessoas visitando a exposição e/ou pelo fato de as pessoas, após visitarem a exposição fisicamente, terem passado a acompanhar o perfil virtual. De qualquer forma, o contato físico com a exposição parece ter contribuído para o aumento do número de alcance de pessoas pelo ambiente virtual.

No entanto, o mesmo não foi observado para o total de curtidas no perfil, que atingiu o maior valor nos dias que antecederam a exposição, conforme demonstrado na figura 5. Um segundo pico ocorreu no início de março, após o início da exposição e coincide com o pico de alcance das publicações mencionado anteriormente. Este valor pode demonstrar que no primeiro contato as pessoas "curtem" o perfil e após isso, podem ou não continuar acompanhando as atualizações de postagens, assim como participar da construção da página deixando comentários. Este clique inicial de curtida do perfil, com pico de 60 pessoas no dia 23/02/2016, revela também que foi possível divulgar o evento com alguns dias de antecedência, porém, nas semanas iniciais da exposição mais pessoas curtiram a página, quando foi alcançado um número maior de pessoas visualizando o perfil.

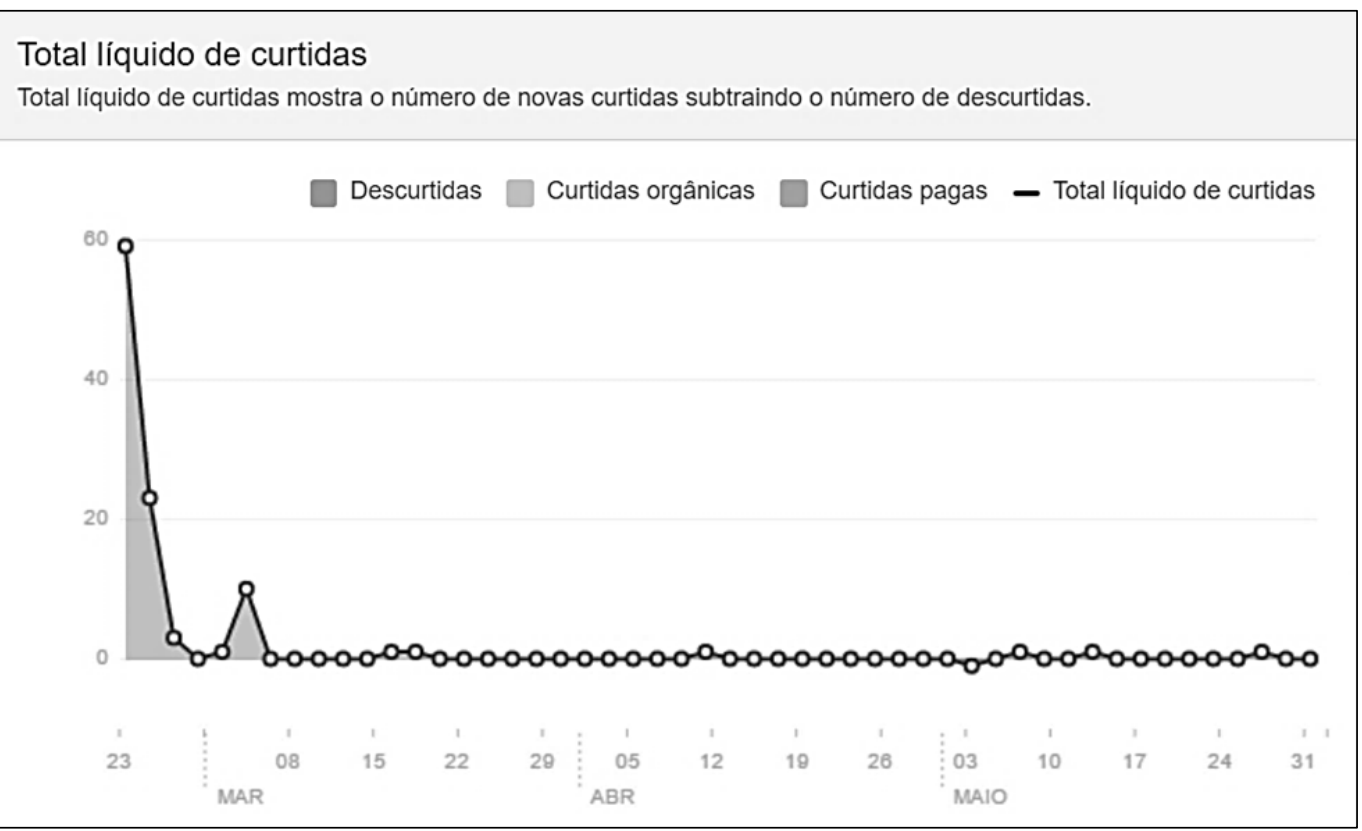

Figura 5 - Gráfico do total de curtidas no perfil da exposição na rede social Facebook ${ }^{\circledR}$ entre 23/02/2016 a 01/06/2016. Fonte: https://www.facebook.com/brasilantartica/insights/

Entre as informações fornecidas pelo Facebook ${ }^{\circledR}$ ao administrador é permitido visualizar mais detalhes sobre quem curte, comenta e compartilha as publicações, sendo que a rede social afirma que é com o intuito de aprimorar o direcionamento das publicações no perfil. Sobre as pessoas que 
seguiram a página da exposição mediada, foco deste estudo, $71 \%$ são mulheres e $28 \%$ homens, estando a maioria na faixa etária de 18 a 24 anos. Deste grupo, 128 pessoas informam no seu perfil do Facebook ${ }^{\circledR}$ que são do município do Rio de Janeiro, ou seja, a maioria dos fãs. Estes dados indicam que o público alcançado pela página possui probabilidade de ser o mesmo que encontramos no curso de Ciências Biológicas da UVA. Tal resultado já era esperado, pois está de acordo com o objetivo da página de promover a divulgação da exposição que foi realizada nesta universidade.

Outra análise que se destaca é em relação às publicações mais curtidas durante o período da exposição. O administrador pode visualizar um resumo das curtidas e alcances das suas publicações, sendo que a publicação de um post com registro fotográfico do dia da abertura da exposição teve o maior número de curtidas. A segunda publicação que atingiu maior repercussão no perfil da exposição foi um link para um vídeo no site YouTube ${ }^{\circledR}$, que consiste em uma animação mostrando o projeto da nova estação brasileira na Antártica. O vídeo compartilhado está relacionado com o incêndio ocorrido em 2012 na Estação Antártica Comandante Ferraz (EACF), que a destruiu quase completamente.

Monteiro (2016) analisando a criação de um perfil no Facebook ${ }^{\circledR}$ considerou que utilizar vídeos do YouTube ${ }^{\circledR}$ de boa qualidade despertou o interesse nos alunos e levou à construção coletiva de novos materiais para estudos. A autora criou um perfil visando oferecer recursos visuais e possibilitar a interação compartilhada de recursos para uma disciplina de um curso de Psicologia e verificou que todos os tópicos estudados superaram as expectativas, tanto quanto ao número de seguidores e de pessoas alcançadas.

Alencar, Moura e Bitencourt (2013) propõem que a inserção de mídias sociais no contexto estudantil se torna uma tarefa fácil, já que os nativos digitais já estão habituados a utilizar as mídias digitais e que se deve considerar que o uso dos espaços virtuais é uma extensão das ações de sala de aula, buscando contextualizar melhor os saberes. Pessoni e Akerman (2014) conduziram uma revisão de trabalhos acadêmicos disponíveis virtualmente focados no uso de mídias sociais no contexto educacional, principalmente o Facebook ${ }^{\circledR}$. Consideraram que, mesmo com espectro pequeno de trabalhos, o campo de pesquisa de aplicação de redes sociais às atividades de ensino e aprendizagem aponta para um aumento da quantidade de estudos sobre este novo assunto, mas que existe uma zona de incertezas produzida pela inovação no ensino.

\section{Conclusão}

Acreditamos que com este estudo foi possível colaborar para o aumento da divulgação de pesquisas brasileiras realizadas na Antártica, visto que este foi um dos objetivos alcançados pela exposição. Com relação aos questionários, dentre as dez perguntas que continha, oito delas aumentaram a porcentagem de acertos no grupo de alunos que respondeu após a visita mediada pela exposição. Esta observação demonstra que os alunos, ao interagirem com os mediadores e visualizarem as peças da exposição, assimilaram conhecimentos que possibilitaram distinguir a resposta certa entre as opções. Observamos também que o uso de exposição mediada como 
instrumento didático pode ser uma forma válida de complementar os conteúdos vistos em sala de aula, uma vez que estes espaços fornecem um ambiente diferente de vivência para os estudantes, tornando mais ricas as suas oportunidades de aprendizagem.

O uso do Facebook ${ }^{\circledR}$ mostrou oferecer modos eficazes de estabelecer uma relação rápida com um grande número de pessoas e é um ambiente virtual que possibilita a interação e construção coletiva de conhecimento de maneira fácil e acessível. As redes sociais podem ser consideradas maneiras ágeis de comunicação que acompanham o estilo de vida atual, considerando tanto o possível uso para o ensino como para entretenimento, porém devem ser usadas com moderação e consciência. A internet, aliada às redes sociais, são recentes formas de circulação de conhecimento em proporções jamais vistas antes, tanto em quantidade como em velocidade. No entanto, muitas vezes, não há nenhum controle sobre a veracidade dos dados acessados, o que requer que os usuários tenham uma interpretação crítica do que leem, buscando sempre fontes variadas e confiáveis de informação.

\section{Agradecimentos}

Gostaríamos de agradecer aos professores: Luiz Antonio C. Rodrigues, Magda F. de AndradeTubino e Danielle Spada Tavares, bem como aos alunos da BIO-UVA: Andreza Souza, Daniel Faustino, Igor Amauri, Janaína Martins, Lucas Gaudie-Ley, Maycon Charbel, Monica Vieira, Renan Goltara, Renatha Cardoso, Thainá Lorrane e Vanessa Valladares pela participação no desenvolvimento do projeto UVA-Gelada. Agradecemos o apoio das instituições acadêmico-científicas Universidade Veiga de Almeida, LARAMG/UERJ, INCT da Criosfera, INCT-APA, APECS-Br e PROANTAR.

\section{Referências}

ALENCAR, G.; MOURA, M. R.; BITENCOURT, R. B. Facebook como plataforma de ensino/aprendizagem: o que dizem os professores e alunos do IFSertão - PE. Educação, Formação \& Tecnologias, v. 6, n. 1, p. 85-92, 2013.

BEIGUELMAN, B. Curso prático de bioestatística. Ribeirão Preto: Fundação de Pesquisas Científicas de Ribeirão Preto (FUNPEC), 2002.

BRASIL. Constituição da República Federativa do Brasil (1988). Título VIII - Da Ordem Social. Capítulo VI - do Meio Ambiente, 1988.

BRASIL. Senado Federal. Lei de Diretrizes e Bases da Educação Nacional: ㄲo 9.394, de 20 de dezembro de 1996.

BRASIL. Ministério da Educação (MEC). Parâmetros Curriculares Nacionais (Ensino Médio). 2000. Disponível em: <http://portal.mec.gov.br/seb/arquivos/pdf/blegais.pdf>. Acesso em: 06 jun. 2016.

BRITO, T. O Brasil e o meio ambiente antártico: ensino fundamental e ensino médio. Brasília: Ministério da Educação, 2006. 
CARAMELLO, N.D.A. et al. Ciência Polar e a Comunicação entre estudantes, educadores e cientistas. Revista Eletrônica Científica da UERGS, v. 3, n. 2, p.340-371, 2017.

KRASILCHIK, M. Práticas de Ensino de Biologia. São Paulo: Editora da Universidade de São Paulo, 2008.

MACHADO, M. C. S.; BRITO, T. Antártica: ensino fundamental e ensino médio. Brasília: Ministério da Educação, Secretaria de Educação Básica, 2006.

MINISTÉRIO DA EDUCAÇÃO - MEC. Base Nacional Comum Curricular. 2017. Disponível em: $<$ http://basenacionalcomum.mec.gov.br>. Acesso em: 28 maio 2018.

MINISTÉRIO DO MEIO AMBIENTE - MMA. O Brasil e o Meio Ambiente Antártico. Brasília: MMA, 2007.

MONTEIRO, D. P. Uso do Facebook ${ }^{\circledR}$ como recurso didático na disciplina Fundamentos de Neuroanatomia: estudo de caso. CRIAREAD, v. 1, n. 1, p. 226- 238, 2016.

OLIVEIRA, S. F. Educação ambiental: aspectos históricos e perspectivas. Boletim Goiano de Geografia, v. 26, n. 2, p. 151-166, 2006.

PESSONI, A.; AKERMAN, M. O uso das mídias sociais para fins de ensino e aprendizagem: estado da arte das pesquisas do tipo survey. ECCOM, v. 5, n. 10, p. 29-42, 2014.

QUEIROZ, G. et al. Construindo saberes da mediação na educação em museus de ciências: o caso dos mediadores do Museu de Astronomia e Ciências Afins / Brasil. Revista Brasileira de Pesquisa em Educação em Ciências, v. 2, n. 2, p. 77-88, 2002.

RODRIGUES, L. A. C. et al. Análise da abordagem do tema "Antártica" em livros didáticos do Ensino Fundamental. In: IV Encontro Nacional de Ensino de Ciências da Saúde e do Ambiente, 2014. Niterói. Anais... Niterói: Campus da Praia Vermelha/Universidade Federal Fluminense, 2014.

SOUZA, R. W. L. Modalidades e recursos didáticos para o ensino de biologia. Revista Eletrônica de Biologia, v. 7, n. 2, p. 124-142, 2014.

SYDNEY, N. V. Desmistificando os mamíferos marinhos: uma ação de popularização da ciência em Campo Largo - PR. Revista da Biologia, v. 1, p. 2-5, 2008.

VERíssimo, A., PEDROSA, A.; RIBEIRO, R. (Coord.). Ensino Experimental das Ciências (Re)pensar o Ensino das Ciências. Lisboa: Ministério da Educação de Portugal, 2001. 